Child protection training

\section{Paediatricians and child protection: the need for effective education and training}

\section{J Bannon, Y H Carter}

\section{"Child protection training is essential for all health professionals engaged in services for children. It is not an optional extra" (Barry Capon, Chair of Independent Inquiry into Death of Lauren Wright)'}

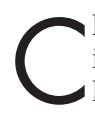
hild maltreatment has become increasingly topical, and recent high profile cases of fatal abuse have attracted considerable attention from the media. ${ }^{2}$ Furthermore, independent inquiries have not only highlighted system failures in the child protection process, but have also been critical of the actions undertaken by health professionals and social workers. The most significant case in this respect is that of Victoria Climbié, whose death at the hands of her carers has prompted a major review of child protection procedures led by Lord Laming. His report is now available and should be carefully considered by all professionals who care for children and their families. ${ }^{3}$ Of a total of 108 recommendations made by Laming, 26 are specific to health. The report refers to poor standards in note keeping, inadequate communication between individuals and agencies, and ineffective and poorly coordinated intervention once child protection concerns are raised. A key message is that a case of suspected abuse or neglect should be treated with the same level of urgency as any other potentially fatal childhood disorder. The importance of child protection training for all relevant health care professionals is stressed. In addition, it is recommended that all consultant paediatricians should be periodically revalidated with respect to management of deliberate harm to children and subsequent multidisciplinary investigation. Relatively little in the Laming report is new. A previously published study of Part 8 reviews has already identified similar themes and conclusions. ${ }^{4}$

\section{DOCTORS AND THE CHILD PROTECTION PROCESS}

The child protection process and associated legislation varies in specific detail from one country to another. However, most systems require clinicians to remain vigilant for the possibility of abuse or neglect, to report concerns to the appropriate authorities, and to actively participate in interagency investigation and intervention. Concern regarding the ability of doctors of all grades and specialties to effectively respond to the presentation of possible child maltreatment has already been documented. ${ }^{5}$ It would appear that even experienced clinicians may fail to recognise and deal with serious instances of abuse, even in the presence of clear clinical indicators. For example, a UK study of infant subdural haemorrhage confirmed that, while most cases were likely to have occurred as a result of intentional injury, not all were appropriately investigated nor referred to Social Services. ${ }^{6}$ Impaired recognition of other forms of abuse, including non-accidental burns and scalds, ${ }^{7}$ and sexual abuse ${ }^{8}$ has also been documented.

If the child protection process is to be effective, then clinicians who encounter a child in possible need of protection must act promptly and make appropriate referrals to statutory agencies. Studies from Canada, ${ }^{9}$ Israel, ${ }^{10}$ and Australia, ${ }^{11}$ however, have documented an apparent reluctance on the part of paediatricians to comply with this requirement, even in countries where this is mandatory.

A further key responsibility for the doctor who suspects abuse or neglect is to carefully document allegations or disclosures, clinical findings, and reasons for concern in case notes as these may be later needed for medicolegal purposes. Research to date would indicate that doctors' skills in this clinical area are also in need of improvement. ${ }^{12}$

The responsibility does not end with reporting. Paediatricians must be prepared to testify in court and defend their views in a professional and unbiased manner. The performance of clinicians in this area has also attracted criticism. ${ }^{13}$

\section{PARTICIPATION IN THE CHILD PROTECTION PROCESS: CHALLENGES}

Most (if not all) clinicians would readily acknowledge the vulnerability of children and endorse processes put in place for their protection. So why then is clinical performance in this area at times a cause for concern? A number of factors, acting in synergy, may explain this inconsistency. There is no doubt that participation in the child protection process is stressful and may deter some doctors from becoming actively involved. ${ }^{15}$ Some may fear the consequences of challenging parents in terms of damage to the doctor-patient relationship. Others will be aware of colleagues who, having invoked child protection investigations, have then become themselves the subject of intimidation and harassment by parents. ${ }^{16}$ Many are wary of testifying in court, an experience that can be challenging, even for experts. ${ }^{17}$ Confidentiality is a fundamental principle, and the concept of sharing sensitive information with outside agencies may be daunting. ${ }^{18}$ Furthermore, child maltreatment is capable of invoking profound emotions, including disbelief, disgust, and anger on the part of the doctor who encounters it. Some doctors have difficulty believing what they see in front of them and professional denial of abuse represents a phenomenon that may be distinct from failure of recognition. ${ }^{19}$ It does not always neatly fit into the traditional medical model of history taking, examination, investigation, and diagnosis. There are many grey areas in child protection work where precise diagnosis is not always possible, and some doctors may feel uncomfortable in dealing with uncertainty. Attitudinal issues are also important and a criticism, already noted, is that some doctors may feel that child protection is the prime responsibility of other individuals or agencies. Furthermore, some clinicians appear reluctant to involve child protection agencies on the basis that doing so would not be in the best interests of a child's welfare. ${ }^{20}$

\section{THE ROLE OF TRAINING}

Perhaps the most significant factor in this context is impaired awareness of child protection issues resulting from inadequate training. Several authors have sought the views of trainees in a variety of front line specialties that have regular contact with children and their families regarding their satisfaction with their training in child abuse and neglect. These surveys have included those training in paediatrics, ${ }^{21}$ accident and emergency medicine, ${ }^{22}$ psychiatry, ${ }^{23}$ and primary care. ${ }^{24}$ Overall conclusions from these studies would indicate that many doctors perceive their training to be unsatisfactory in either quantity or in focus. In particular, many are confused regarding their specific role in the child protection process, are uncertain as to what they should do and say when they encounter abused children, and are uncertain regarding the consequences (positive or otherwise) of involving outside agencies. A study of general practitioner (GP) registrars in vocational 
training schemes that included paediatrics in London revealed significant deficiencies in their child protection training, and a minority expressed confidence at the prospect of dealing with child protection cases in the future as GP principals. ${ }^{25}$

\section{WHY TRAINING IS NEEDED AND HOW IT SHOULD BE DELIVERED}

Effective participation in child protection work requires a range of clinical competencies in terms of history taking, clinical examination, documentation, communication skills, and decision making ability. Confidence and courage are needed to effectively confront abusing carers. Clinicians also need to cope with their own emotional responses provoked by disturbing cases of child maltreatment. Effective education and training should not only provide the knowledge and skills required to address these challenges, but also promote the development of appropriate attitudes and perceptions regarding the doctor's role in the protection of children from abuse or neglect. There is a limited amount of research that has shown the effectiveness of child protection training in this regard, at least in the short term. ${ }^{26-28}$ The stakes in child protection are high, and the consequences of inappropriate management can have disastrous consequences for children, their families, and involved professionals.

In order that child protection training is effective in ensuring that paediatricians and other clinicians respond effectively when confronted by child maltreatment, the following principles are suggested:

(1) Child protection should be viewed as representing a critical component of training of equivalent importance to Advanced Life Support.

(2) Training must be offered to all doctors who have contact with children and their families. It should be remembered that doctors in disciplines other than child health may also encounter children in need of protection, including general practitioners, accident and emergency staff, genitourinary physicians, obstetricians, gynaecologists, and both general and orthopaedic surgeons.

(3) The precise content and scope of training will vary according to the seniority of recipients and their role in delivery of health care to children and their families. The following levels of training might be considered:

- Basic, consisting of a short introduction (one hour), including an overview of local protocols and sources of help and advice, would be offered to all doctors and might be included in hospital and departmental inductions.
- Standard would require a day's training and would focus on minimum competencies in knowledge, skills, and attitudes required of senior house officers.

- Advanced would include the preceding, but in more detail, and would be suitable for senior paediatric registrars and consultants; legal aspects, including court proceedings would also be covered.

- Named/designated doctor training would address the needs of those who have a special interest in child protection; this might consist of modular training, leading to postgraduate qualification (diploma or MSc); such an approach is being considered in the USA. $^{29}$

(4) Training could be developed by adopting approaches already successfully utilised by other core training programmes, for example, the Advanced Paediatric Life Support. There is much to be said for a universally recognised programme that has common and agreed aims, content, and method of delivery. The Royal College of Paediatrics and Child Health ( $\mathrm{RCPCH}$ ) has convened a working party to consider the development of such a course.

(5) The scope of training may need to be broadened in several respects. For example, some authorities feel that paediatricians should possess an awareness of domestic violence and its adverse effects on child development and welfare ${ }^{30}$ Furthermore, clinicians need to have an awareness of variations in childcare practices that exist between different cultural groups. ${ }^{31}$ Training should also acknowledge current thinking on the aetiology of different forms of abuse. ${ }^{32} 33$ (6) We must identify and promote those educational interventions that are shown to be effective. To date, only a limited amount of research has been undertaken in this area, and has been confined to short term changes in knowledge and sometimes in attitudes of trainees. ${ }^{34}$ Little is currently known about the long term effectiveness of child protection training in terms of influencing clinician behaviour.

\section{CONCLUSIONS}

A collaborative approach between all those with a remit for medical education is needed to ensure consistency of approach. It is encouraging that a position paper on the role of primary care in child protection has been jointly defined by the Royal College of General Practitioners, the RCPCH, and the National Society for the Prevention of Cruelty to Children. $^{35}$ Both uniprofessional and interdisciplinary teaching (to include clinical teams of nurses, therapists, and administrative staff) are required. A variety of teaching methods (didactic, interactive, and distance learning based) should be considered and evaluated. It is self evident that adequate sources of secure funding to support this initiative must be identified.

It would be naïve to suggest that every instance of fatal abuse would be prevented if the above measures were implemented. There is a perception that factors such as family violence and insufficient support for vulnerable families are outside the control of paediatricians. This may often be the case; however, provision of effective education and training without doubt lies within our remit. In this respect, Lord Laming's report represents not only a challenge for paediatricians, but also an opportunity to ensure improved protection for children.

Arch Dis Child 2003;88:560-562

\section{Authors' affiliations}

M J Bannon, Consultant Paediatrician, Northwick Park Hospital \& Associate Dean London Deanery, UK

Y H Carter, Professor of General Practice and Primary Care, Barts and the London, Queen Mary's School of Medicine and Dentistry, London, UK

Correspondence to: Dr M J Bannon, London Deanery, 20 Guilford Street, London WC1N 2DZ, UK

mbannon@londondeanery.ac.uk

\section{REFERENCES}

1 Anon. Doctor's arrogance blamed for girl's death. Daily Telegraph, 28 March 2002.

2 Anon. MP proposes reform to stop more Climbié cases. Guardian, 20 May 2002.

3 Anon. http://www.victoria-climbie-inquiry. org.uk/finreport/finreport.htm.

4 Anon. http://www.doh.gov.uk/acpc/ learningcasereviews.pdf.

5 Warner JE, Hansen DJ. The identification and reporting of physical abuse by physicians: a review and implications for research. Child Abuse Negl 1994:18:11-25.

6 Jayawant S, Rawlinson A, Gibbon F, et al. Subdural haemorrhages in infants: a population based study. BM 1998:317:1558-61.

7 Benger JR, McCabe SE. Burns and scalds in pre-school children attending accident and emergency: accident or abuse? Emerg Med J 2001;18:172-4

8 Davies E, Seymour F. Medical evaluations in cases of suspected child sexual abuse: referrals and perceptions. N Z Med J $2001 ; 114: 334-5$.

9 Vulliamy AP, Sullivan R. Reporting child abuse: pediatricians' experiences with the child protection system. Child Abuse Negl 2000;24:1461-70.

10 Shor R. Pediatricians in Israel: factors which affect the diagnosis and reporting of maltreated children. Child Abuse Negl 1998;22:143-53.

11 Van Haeringen AR, Dadds $M$, Armstrong KI The child abuse lottery ... will the doctor suspect and report? Physician attitudes towards and reporting of suspected child abuse and neglect. Child Abuse Negl 1998;22:159-69.

12 Limbos MAP, Berkowitz CD. Documentation of child physical abuse: how far have we come? Pediatrics 1998;102:43-58.

13 Williams $\mathbf{C}$. The role of the expert witness. Arch Dis Child 2002;87:267-8. 
14 Dyer C. Judge criticises paediatrician for "overstating" sex abuse allegations. BM 2002;325:235

15 Johnson CF. Child abuse as a stressor of pediatricians. Pediatr Emerg Care 1999:15:84-9.

16 Marcovitch H. Diagnose and be damned. BM 1999;319:1376

17 Meadow R. A case of murder and the BM. BM 2002; $324: 41-3$.

18 van Veenendaal E. Child abuse: does disclosing the fact have implications for medical secrecy? Medicine \& Law 1993;12:25-8.

19 Leventhal JM. The challenges of recognizing child abuse: seeing is believing. JAMA 1999;281:621-6.

20 Marshall WN, Locke C. Statewide survey of physician attitudes to controversies about child abuse. Child Abuse Negl 1997;21:171-9.

21 Woolf A, Taylor L, Melnicoe L, et al. What residents know about child abuse? Implications of a survey of knowledge and attitudes. Am J Dis Child 1988;142:668-72.

22 Biehler JL, Apolo J, Burton L. Views of pediatric emergency fellows and fellowship directors concerning training experiences in child abuse and neglect. Pediatr Emerg Care $1996 ; 12: 365-9$.
23 Barnard-Thompson $\mathrm{K}$, Leichner $\mathrm{P}$. Psychiatric residents' views on their training and experience related to child abuse. Can J Psychiatry 1999;44:769-74.

24 Bannon MJ, Carter YH, Barwell F, et al Perceptions held by general practitioners in England regarding their training needs in child abuse and neglect. Child Abuse Review 1999;8:276-83.

25 Bannon MJ, Carter YH, Jackson NR. Meeting the training needs of GP registrars in child abuse and neglect. Child Abuse Review $2001 ; 10: 254-61$.

26 Lawrence LL, Brannen SJ. The impact of physician training on child maltreatment reporting: a multi-specialty study. Military Medicine 2000;165:607-11

27 Dubowitz H, Black M. Teaching pediatric residents about child maltreatment. J Dev Behav Pediatr J 1991;12:305.

28 Cheung KF, Stevenson KM, Leung P. Competency-based evaluation of case-management skills in child sexual abuse intervention. Child Welfare 1991:70:425-35

29 Starling SP, Sirotnak AP, Jenny C. Child abuse and forensic pediatric medicine fellowship curriculum statement. Child Maltreat 2000:5:58-62.
30 Knapp JF, Dowd MD. Family violence: implications for the pediatrician. Pediatr Rev 1998;19:316-21.

31 Debelle G. Child protection in a multicultural society. In: Bannon M, Carter YH, eds. Protecting children from abuse and neglect in primary care. Oxford: Oxford University Press, 2002

32 Southall DP, Samuels MP, Golden MH. Classification of child abuse by motive and degree rather than type of injury. Arch Dis Child 2003;88:101-4

33 Golden MH, Samuels MP, Southall DP. How to distinguish between neglect and deprivational abuse. Arch Dis Child 2003;88: 105-7.

34 Cohn F, Salmon ME, Stobo JD, eds. Confronting chronic neglect: the education and training of health professionals on family violence. Washington, DC: National Academies Press, 2002

35 Carter YH, Bannon M. The role of primary care in the protection of children from abuse and neglect. London: RCGP Publications, 2003.

\section{IMAGES IN PAEDIATRICS.}

\section{From Cosette to Climbié: "Progress is the aim, the ideal is the model"}

n Hugo's Les Misérables (1862), Cosette, a neglected and abused orphan is rescued from her exploitative carers by Jean Valjean who devotes his life to raising and caring for her.

This picture taken from the late nineteenth century is a timeless illustration of the exploitation and abuse of children, everywhere and at any time in history.

"The whole person of this child, her gait, her attitude, the sound of her voice, the intervals between one word and another, her looks, her silence, her least motion, expressed and uttered a single idea: fear."1

As we read the Victoria Climbié report 140 years later, we pause and wonder whether things have really changed.

Of course we're all more aware now, but that doesn't make it any easier to consider, especially as the most likely scenario is another report sometime in the future on yet another child who was failed by the state.

Then we slowly realise this picture has a relevance beyond the single named child, embracing instead far too many children in the world. And whether we like it or not, all of us share some blame. One child's unnecessary death is a tragedy; the death of millions becomes devalued to a mere statistic. The injustice of poverty in the developing world, our complaisance in the exploitation through unfair trade barriers, and the sanctioning by large multinationals of child labour (whose goods we willingly buy) are just a few examples. In the mid nineteenth century Hugo saw "the three problems of the age - the degradation of man by poverty, the ruin of woman by starvation and the dwarfing of childhood by physical and spiritual night."

As child health professionals our role is not restricted to "our patch" but in endeavouring to improve the health of children everywhere.

A N Williams Child Development Centre, Northampton General Hospital, Northampton NN1 5BD, UK; anw@doctors.org.uk



Original illustration of the character Cosette by Emile Bayard (1837-91) from the novel Les Misérables by Victor Hugo. The inspiration behind the world famous theatre poster for the musical Les Misérables.

\section{Reference}

1 Hugo V. Les Misérables. Sceptre Editon, Hodder and Stoughton, 1998:349. 